\title{
Operação em Mercados Futuros e Lucratividade da Propriedade Rural: Análise baseada nos Custos de Produção de Café
}

\begin{abstract}
Larissa Ananda Paiva Maciel
Mestrado em Administração pela Universidade Federal de Rondônia - UNIR Professora do Instituto Federal de Educação Ciência e Tecnologia de Rondônia - IFRO Avenida Governador Jorge Teixeira, no 3142. Industrial. Porto Velho/RO. CEP: 76821-

002

E-mail: laripaiva88@gmail.com

Carlos André da Silva Müller

Doutorado em Economia Aplicada pela Universidade Federal de Viçosa - UFV

Professor da Universidade Federal de Rondônia - UNIR

Rodovia BR 364, Km 9,5. Campi José Ribeiro Filho. Porto Velho/RO. CEP: 76800-000

E-mail: carlosandre@unir.br

Rosália Maria Passos da Silva

Doutorado em Administração pela Universidade Federal do Rio Grande do Sul - UFRGS

Professora da Universidade Federal de Rondônia - UNIR Campus Universitário Antonio Ribeiro Filho. Porto Velho/RO. CEP: 78900-000

E-mail: rosalia@unir.br
\end{abstract}

\section{RESUMO}

Os mercados futuros agropecuários são entendidos como uma ferramenta fundamental para a gestão do risco de preços, a partir dos quais cooperativas e agricultores têm a possibilidade de reduzir riscos de volatilidade de preços, por meio de estratégias de hedge. Entretanto, o uso do mecanismo é bastante reduzido entre produtores rurais. Esta pesquisa teve a finalidade de compreender como a atuação em mercados futuros é capaz de afetar a lucratividade rural com base nos cálculos dos custos de produção de café robusta de Cacoal, em Rondônia. Buscou-se calcular estratégias de hedge de mínima variância por meio do Modelo Vetorial Autorregressivo para determinação do preço efetivo, bem como foi construída a planilha de custos da produção média dos produtores. Probabilisticamente, os resultados indicam que os impactos sobre a lucratividade estão concentrados em torno do preço à vista do produtor, caso não opte pela operação em mercados futuros. Conclui-se que a operação conjunta de atuação em mercados futuros e comercialização física não representa impactos tanto negativos quanto positivos na lucratividade do produtor rural de café de Cacoal. Portanto, esse não pode ser o argumento de não atuação em mercados futuros, mesmo considerando a distância dessa praça para o mercado tradicional.

Palavras-chave: Mercados futuros. Custos de produção. Café. 
Operação em Mercados Futuros e Lucratividade da Propriedade Rural: Análise baseada nos

Custos de Produção de Café

Larissa Ananda Paiva Maciel, Carlos André da Silva Müller, Rosália Maria Passos da Silva

Future Markets Operation and Rural Property Profitability: Analysis based on Coffee Production Costs

\begin{abstract}
The agricultural future markets are seen as a fundamental tool for managing price risk, from which cooperatives and farmers are able to reduce the volatility price risk through hedging strategies. However, the use of the mechanism is quite low among farmers. This research aimed to understand how the future markets operation can affect rural profitability based on the calculations of the robusta coffee production costs of Cacoal, in Rondônia. We tried to calculate hedging strategies of minimum variance using Vector Auto-Regressive Model for determining the effective price, and built a cost spreadsheet average production of the producers. Probabilistically, the results indicate that the impacts on profitability are concentrated around the spot price of the producer, if he does not opt for operation in future markets. It is concluded that the joint future and physical markets operation does not represent both positive and negative profitability impacts to farmer's Cacoal coffee. Therefore, this may not be the argument of not acting in the future markets, even considering the distance from this place to the traditional market.
\end{abstract}

Keywords: Future Markets. Production Costs. Coffee.

\title{
1 CONTEXTUALIZAÇÃO
}

Os Mercados Futuros agropecuários são entendidos como uma ferramenta fundamental para a gestão do risco de preços. Por meio do uso desse mecanismo, cooperativas, agricultores e empresas têm a possibilidade de reduzir riscos no que tange à volatilidade de preço, em especial no setor agropecuário. Conforme asseveram Müller et al. (2009), há que se considerar uma inevitável variabilidade nos preços de commodities agrícolas, cujas características têm fontes de origens diversas, como condições climáticas, acentuadas mudanças em variáveis macroeconômicas e a conjuntura internacional, que certamente repercutem no equilíbrio entre oferta e demanda desses produtos.

Hedge é entendido como um mecanismo de proteção (redução de riscos) a um determinado ativo, especialmente o de volatilidade de preços. Ainda que antecede a 
criação dos mercados derivativos, o termo passou a ser amplamente utilizado nestes últimos para distinguir a intenção dos operadores como: hedger (vendedor de riscos), arbitrador (gerador de liquidez por atuar em dois ou mais mercados) e especulador (comprador de riscos) (BRESSAN, 2004; HULL, 1996; FARHY, 1999).

$\mathrm{Da}$ atuação em mercados futuros, surge o conceito de preço efetivo, entendido como o resultado final da operação em mercados futuros em conjunto com a variação dos preços do mercado físico à vista (HULL, 1996). São inúmeros os estudos que demonstram a eficiência da utilização de estratégias de hedge para minimização de volatilidade de preços (TONIN et al., 2009; MÜLLER et al., 2009; AGUIAR, 2003; BORELLA, 2004; FILENI et al.,1999).

No entanto, a atuação em mercados futuros, por parte de pequenos produtores rurais, sempre foi um assunto controverso na literatura que trata de estratégias de hedge. Os apontamentos mais frequentes centram-se na assimetria de informação e aversão ao risco como motivos para não atuação nesses mercados (ZEN et al., 2005; FASIABEN et al., 2003; CARVALHO, M. L. S.; GODINHO, M. L. F., 2005). Certamente, a complexidade do mecanismo interfere negativamente no uso de contratos futuros. Entretanto, pesquisas recentes como as de Cruz Júnior (2009) e Brasil (2011) indicam caminhos diferentes dessa visão mais tradicional, acrescentando o elemento cognitivointerpretativo dos motivos pelos quais pequenos produtores atuam ou não em mercados futuros.

De certo, tem se observado que esse mecanismo de gestão de riscos ainda não é plenamente aproveitado por grande parte dos agentes econômicos envolvidos nesses mercados, em especial produtores rurais. Este fato ocorre em razão da imperfeita compreensão acerca da natureza das flutuações dos preços, que, se não podem ser evitadas, ao menos deveriam ser melhor gerenciadas pelos agentes econômicos (LAMOUNIER, 2002).

Com fundamento no que prescreve a teoria de mercados futuros, a atuação provavelmente reduz riscos de volatilidade de preços de café; todavia, poucos pequenos produtores lançam mão dessa ferramenta. Embora haja motivações para 
Operação em Mercados Futuros e Lucratividade da Propriedade Rural: Análise baseada nos

Custos de Produção de Café

Larissa Ananda Paiva Maciel, Carlos André da Silva Müller, Rosália Maria Passos da Silva

esse fato, não está claro qual seria o comportamento da lucratividade do produtor caso participasse no mercado, considerando seu orçamento rural.

Entretanto, para muitos produtores, o orçamento rural é algo rudimentar ou intuitivo, o que impede a definição clara de lucro e, como consequência, resistência na atuação em mercados futuros. Entende-se, portanto, relevante inferir a relação existente entre participar em mercados futuros e sua lucratividade por atuar no cultivo de café, uma vez que esta atuação pode salvaguardá-los das constantes volatilidades no preço da commodity, traduzindo-se em rendimentos mais seguros e menores custos de transação.

Diante do exposto, o objetivo geral deste trabalho foi analisar a lucratividade gerada pelo café robusta no Município de Cacoal/RO, diante da possibilidade do produtor rural em utilizar os Mercados Futuros como ferramenta para a redução de riscos de comercialização. Especificamente, foram perseguidos os seguintes objetivos específicos: (a) identificar o preço efetivo da saca de café por meio de estratégia de hedge; (b) analisar o orçamento do produtor rural; e (c) mensurar a lucratividade gerada pela substituição do preço à vista pelo preço efetivo no orçamento do produtor rural.

\section{REFERENCIAL TEÓRICO-EMPÍRICO}

\subsection{Riscos e mercados futuros}

Uma organização, independentemente de sua natureza (rural ou urbana), incorre em três tipos de riscos por suas atividades produtivas, que podem ser categorizados de acordo com suas fontes, podendo ser definidos como: Riscos Operacionais, Riscos Estratégicos e Riscos Financeiros. O Risco Operacional está relacionado a possíveis perdas, como resultado de sistemas e controles inadequados, falhas de gerenciamento e erros humanos. São aqueles ligados, de alguma forma, ao curso produtivo da empresa. São provavelmente os mais complexos para serem tratados, pela sua amplitude. Os Riscos Estratégicos estão relacionados com mudanças fundamentais no cenário econômico ou político (COIMBRA, 2004). 
Operação em Mercados Futuros e Lucratividade da Propriedade Rural: Análise baseada nos

Custos de Produção de Café

Larissa Ananda Paiva Maciel, Carlos André da Silva Müller, Rosália Maria Passos da Silva

Os Riscos Financeiros são categorizados em riscos de mercado, riscos de crédito e riscos de liquidez. Risco de crédito representa a probabilidade de a contraparte não honrar seus compromissos; o risco de liquidez representa o risco de não conseguir honrar passivos em decorrência de dificuldades de caixa; por fim, o risco de mercado é o risco de perdas em decorrência de flutuações de taxas de juros, taxas de câmbio, preços de ações e commodities (COIMBRA, 2004; BORELLA, 2004).

Os três tipos de risco apresentados estão presentes nas atividades agropecuárias. O risco de produção-clima, pragas e outros (risco operacional), interferência das políticas governamentais na produção agropecuária (riscos estratégicos) e oscilação do preço de uma commodity (como exemplo, de risco de mercado dentro de riscos financeiros) (BORELLA, 2004; BURGO, 2005).

No que se refere à oscilação de preços de produtos agropecuários, os mercados futuros são indicados como mecanismos eficientes para mitigar a volatilidade de preços e, como consequência, a rentabilidade agropecuária, conforme informa Aguiar (2003). A negociação em Mercados Futuros pode assumir três formas: contrato a termo, contratos futuros e opções. O contrato a termo corresponde à compra e à venda de um determinado ativo, por um preço previamente firmado para uma entrega futura. $\mathrm{O}$ término da obrigação desse contrato cessa pela entrega física do ativo ou pela liquidação financeira final. Esse contrato tem por finalidade reduzir o risco sobre o preço futuro de mercadorias negociadas. Não apresenta uma padronização, uma vez que suas características variam de um contrato para outro, em atendimento à vontade das partes (MARTINS, 2005).

Opção, por sua vez, é um instrumento que dá a seu titular um direito sobre algo, mas não uma obrigação, isto é, o lançador de opção de venda de um determinado ativo tem o direito de vendê-lo, entretanto, caso as condições de mercado favoreçam a manutenção do ativo, o agente econômico terá essa opção (CARVALHO, 1999).

Contratos futuros são definidos como o compromisso de comprar ou vender determinado produto, em uma data específica, com o prévio estabelecimento do preço. O contrato futuro é negociado em bolsas de mercadorias e futuros e, em termos, são 
padronizados. Dentre esses termos, destacam-se a qualidade e a quantidade do ativo negociado, bem como sua forma de entrega, o vencimento, as cotações dos preços, os limites de oscilação diária de preços e os limites de posição diária. Os possuidores de um compromisso de venda têm uma posição vendida (short) e os detentores de um compromisso de compra mantêm uma posição comprada (long) (MARTINS, 2005; HULL, 1996).

São três os agentes econômicos que negociam contratos futuros: os hedgers, os especuladores e os arbitradores. Os hedgers são agentes que fazem uso das bolsas como forma de obter garantias para suas operações no mercado físico, como os produtores rurais, exportadores, processadores, entre outros. Especuladores e arbitradores são investidores que participam em bolsas de mercadorias e futuros, com o propósito de obter lucro, e têm a finalidade de trazer informações e liquidez aos mercados. São considerados compradores de riscos, na medida em que os hedgers os vendem. Conforme Bressan (2004, p. 3):

Com o intuito de administrar riscos de mercado (oscilação de preços), o mercado futuro permite a permuta destes riscos com especuladores, apresentando-se como importante instrumento de segurança e sinalização de preços para todos os participantes da cadeia agroindústria.

Para esta pesquisa, um conceito importante é o de base, de onde se deriva o conceito de preço efetivo. A Figura 2 ilustra como o preço efetivo é definido. 


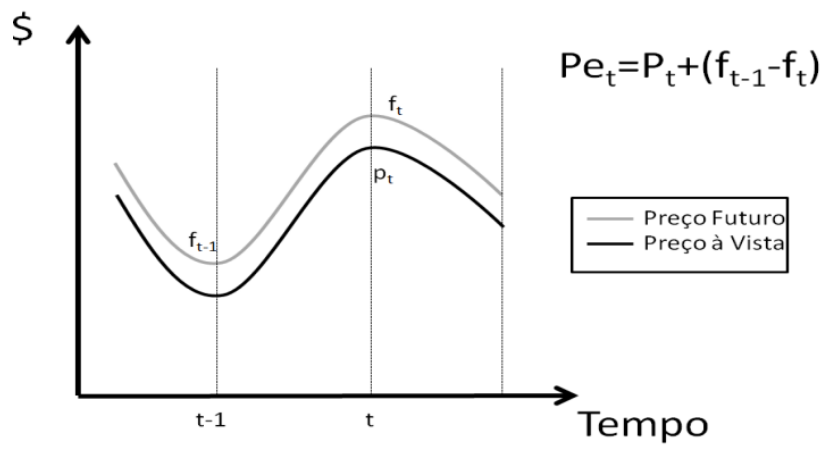

Figura 1: Evolução do preço efetivo ao longo do tempo Fonte: Elaborado pelos autores, com base em Hull (1996).

Conforme explica Hull (1996), a base é definida pela diferença entre os preços futuros (determinados pela negociação dos contratos futuros) e à vista (na comercialização física). O preço efetivo está diretamente relacionado à variação da base ao longo do tempo. Um vendedor de contratos futuros pode fazê-los no momento $t$-1 (Figura 2) e fixa o valor de sua mercadoria. Caso, no momento $t$, esse mesmo vendedor queira se desfazer da sua posição em mercados futuros, ele compraria contratos futuros na mesma quantidade e liquidaria sua posição. Nesse caso, o agente econômico compraria contratos apreciados em relação à sua venda; portanto, "perderia" nos mercados futuros, mas "ganharia" no mercado à vista também pela elevação dos preços.

O resultado final depende da diferença da base nos dois períodos. Certamente, o resultado inverso é também possível, isto é, se os preços futuros e à vista depreciarem, e o agente perceber queda nos preços e comprar contratos mais baratos (ganhos), embora tenha que vender sua mercadoria também com preços menores (perdas) ${ }^{1}$. Para que um hedge seja efetivo, deve existir uma coerência no percurso dos preços à vista e futuros; caso haja um "descolamento" entre esses preços, o agente não garantirá a fixação de seu preço, passando a correr o denominado risco de base (BITENCOURT et al., 2006).

${ }^{1}$ A definição de base e preço efetivo está mostrada nos procedimentos metodológicos. 
Operação em Mercados Futuros e Lucratividade da Propriedade Rural: Análise baseada nos

Custos de Produção de Café

Larissa Ananda Paiva Maciel, Carlos André da Silva Müller, Rosália Maria Passos da Silva

\subsection{Custos de produção do cultivo do café}

O cálculo dos custos de produção é a radiografia de uma empresa rural. Esta radiografia traduz, em valores monetários, o desempenho da atividade e denuncia o grau de eficiência de sua administração. Em outras palavras, o custo de produção vai determinar se um produtor rural está atingindo o lucro como seu objetivo final.

O custo de produção é entendido como a soma dos valores de todos os recursos (insumos) e operações (serviços) utilizados no processo produtivo de uma atividade agrícola (HOFFMAN et al.,1987). O estudo dos custos tem a finalidade de verificar como os recursos empregados em um processo de produção são remunerados, possibilitando também observar como está a rentabilidade da atividade, comparada a alternativas de emprego de tempo e capital (LOPES e CARVALHO, 2000).

A estrutura dos custos de produção é composta de custos fixos e variáveis. Os custos dos recursos necessários para a produção que variam em função do volume produzido e que podem sofrer variações no curto prazo ou que tenham duração igual ou menor que o ciclo de produção são chamados de custos variáveis (CV). Na pecuária de corte, são exemplos: energia elétrica, alimentação dos animais, mão de obra temporária. O somatório de todos os custos variáveis é chamado de Custo Variável Total (CVT) (SOUZA et al., 1989). O custo dos recursos necessários para a produção que não variam em um curto prazo, independentemente do volume de produção que se tenha ou que tenham duração superior ao ciclo de produção, são conhecidos como custos fixos (CF) (LEFTWICH, 1974). São exemplos destes: mão de obra fixa, impostos, depreciações. O somatório de todos os custos fixos envolvidos no processo é chamado de Custo Fixo Total (CFT). Existe ainda o conceito de Custo Operacional (CO) que engloba o valor dos insumos consumidos, o custo de uso de máquinas e implementos utilizados (sem considerar juros) e o valor da mão de obra, ou seja, representa todos os custos que operacionalizam a atividade.

Para o controle de custos, deve-se então montar um centro de custo, que nada mais é que uma relação de todos os itens que geram despesas e receitas na atividade, tendo seus números em unidades físicas de produção e respectivos valores 
Operação em Mercados Futuros e Lucratividade da Propriedade Rural: Análise baseada nos

Custos de Produção de Café

Larissa Ananda Paiva Maciel, Carlos André da Silva Müller, Rosália Maria Passos da Silva

monetários, sendo rigidamente controlados para que, ao fim de um ciclo produtivo, se possa saber qual foi o lucro, ou prejuízo, obtido naquela atividade.

\section{METODOLOGIA}

A primeira etapa deste trabalho consistiu em definir a estratégia de hedge de mínima variância, ou razão de hedge, como proporção de contratos futuros em relação à produção física que minimiza a volatilidade de preços. Para o cálculo, ordenaram-se os dados por data de vencimento do contrato futuro (a BM\&FBovespa define os meses de março, maio, julho, setembro e dezembro), considerando três meses de vencimento de cada contrato. Após realizados esses ajustes, a organização histórica dos dados foi elaborada considerando a janela de análise de 5 contratos anteriores, conforme Quadro 1 a seguir.

\begin{tabular}{|c|c|c|}
\hline Contrato & Dados & Janela de análise \\
\hline Março & $\begin{array}{c}\text { Negociações deste contrato nos meses de } \\
\text { dezembro, janeiro e fevereiro }\end{array}$ & $\begin{array}{c}\text { Contratos de março (ano anterior), maio, } \\
\text { julho, setembro e dezembro }\end{array}$ \\
\hline Maio & $\begin{array}{c}\text { Negociações deste contrato nos meses de } \\
\text { fevereiro, março e abril }\end{array}$ & $\begin{array}{c}\text { Contratos de maio (ano anterior), julho, } \\
\text { setembro, dezembro e março }\end{array}$ \\
\hline Julho & $\begin{array}{c}\text { Negociações deste contrato nos meses de } \\
\text { abril, maio e junho }\end{array}$ & $\begin{array}{c}\text { Contratos de julho (ano anterior), } \\
\text { setembro, dezembro, março e maio }\end{array}$ \\
\hline Setembro & $\begin{array}{c}\text { Negociações deste contrato nos meses de } \\
\text { junho, julho e agosto }\end{array}$ & $\begin{array}{c}\text { Contratos de setembro (ano anterior), } \\
\text { dezembro, março, maio e julho }\end{array}$ \\
\hline Dezembro & $\begin{array}{c}\text { Negociações deste contrato nos meses de } \\
\text { setembro, outubro e novembro }\end{array}$ & $\begin{array}{c}\text { Contratos de dezembro (ano anterior), } \\
\text { março, maio, julho e setembro }\end{array}$ \\
\hline
\end{tabular}

Quadro 1: Organização histórica dos dados de preços futuros de café arábica e, à vista, de café robusta de Cacoal, Rondônia

Fonte: Elaborado pelos autores.

Entre as opções para calcular a razão de hedge para este trabalho, estavam a Regressão Linear Simples (ENDERINGTON, 1979), o Modelo Vetorial Autorregressivo (HERBST et al., 1993) e o Modelo Linear de Correção de Erro (MYERS e THOMPSON, 1989; GOSH, 1993; MULLER et al., 2009). Entre as alternativas, optou-se pelo Modelo Vetorial Autorregressivo, porque teve melhor efetividade em relação à Regressão 
Linear Simples e porque não foi possível encontrar cointegração entre as variáveis, impedindo o uso desse último modelo.

A equação utilizada foi:

$$
\Gamma_{t}=\mathrm{A}+\sum_{i=1}^{k} \mathrm{~B}_{k} \Gamma_{t-i+1}+U_{t}
$$

em que:

$\Gamma$ é o vetor $2 \times 1$, que representa os retornos percentuais dos valores dos contratos futuros de café arábica $\left(R\left(p_{f, t}\right)\right)$ e das negociações à vista desse produto ( $R\left(p_{s, t}\right)$ ); A é o vetor $2 \times 1$ que representa as constantes $a_{f}$ (do vetor autorregressivo de $R\left(p_{f, t}\right)$ ) e $a_{s}$ (do vetor autorregressivo de $R\left(p_{s, t}\right)$ ); $\mathrm{B}$, matriz quadrada $2 \times 2$, representa os coeficientes $b_{1 k}, b_{2 k}, b_{3 k}, b_{4 k}$ estimados; e $U_{t}$ é o vetor $2 \times 1$, que representa os resíduos $u_{f}$ para $R\left(p_{f, t}\right)$ e $u_{s}$ para $R\left(p_{s, t}\right)$, tendo média zero e uma matriz de variância e covariância positivas, definidas e constantes $\left(E\left(U_{t} U_{t}{ }^{\prime}\right)=\Sigma_{U}\right)$, ou seja, os resíduos são vetores estocásticos com $U \sim\left(0, \Sigma_{U}\right)$.

Uma vez obtidos esses resultados, foi possível construir a equação de preço efetivo adaptado à estratégia de hedge. Partindo do pressuposto de que o preço efetivo, segundo Barros e Aguiar (2005), é dado por:

$p e_{t}=p_{t+}\left(f_{t-1}-f_{t}\right)$,

em que pe é o preço efetivo no período $t ; p_{t}$ o preço da mercadoria à vista no período $t$ e $\left(f_{t-1}-f_{t}\right)$ a diferença dos preços de contratos futuros entre $t-1$ e $t$. No momento em que um produtor rural vende contratos futuros, $t$ e $t-1$ são iguais, portanto pe é igual a $p_{t}$. No entanto, nessa equação, a quantidade de contratos futuros é igual à quantidade de mercadorias a ser negociada. Como se pressupôs que o produtor realizou estratégia de 
hedge de mínima variância, é preciso acrescentar o fator $h$, que representa a proporção de contratos futuros em relação à comercialização. Assim, tem-se:

$p e_{t}=p_{t+}\left(f_{t-1}-f_{t}\right)^{*} h$

Considerando que a base é a diferença entre o preço futuro multiplicado pela proporção de contratos futuros em relação à comercialização física, menos o preço $\left(b_{t}=f_{t}^{*} h-p_{t}\right)$, o preço efetivo calculado para essa pesquisa foi:

$p e_{t}=f_{t-1}^{*} h+b_{t}$

O lucro do produtor rural é dado pela equação:

$I_{t}=p_{t}^{*} Q_{t}-C_{t}$,

em que $l_{t}$ é o lucro da propriedade rural; $p_{t}$, o preço à vista do produto; $Q_{t}$, a quantidade comercializada; $\mathrm{C}_{\mathrm{t}}$, os custos de produção. Portanto, nesta etapa, o preço negociado no mercado à vista foi substituído pelo preço efetivo calculado anteriormente, entendido como o preço de uma carteira de ativos contendo contratos futuros de café e sua mercadoria física.

Os dados de negociação de café robusta na praça de Cacoal foram obtidos junto à Safras e a Mercados, enquanto que os preços futuros, junto à BM\&FBovespa. Como estes últimos estão em dólar, os preços à vista de Cacoal foram dolarizados, utilizando os dados da Gazeta Mercantil.

Após essa etapa de escritório, foi realizada pesquisa de campo para construir os custos de produção de 24 propriedades rurais produtoras de café no município de Cacoal. A amostra foi intencional, não probabilística. Contou-se com o apoio de técnicos da Associação de Assistência e Extensão Rural do Estado de Rondônia (EMATER/RO), os quais indicaram a Linha 21 da Rodovia do Café como sendo uma 
das mais produtivas da região. Trata-se de uma comunidade composta basicamente por agricultores descendentes da Pomerânia (região histórica situada entre a Alemanha e a Polônia) que migraram para a região após a $2^{\underline{a}}$ Guerra Mundial e que têm no cultivo de café e na pecuária leiteira suas principais fontes de renda.

$\mathrm{Na}$ pesquisa de campo, foi aplicado um formulário que procurou sistematizar toda a orçamentação do cultivo do café. Uma vez obtidos os dados, os mesmos foram agrupados de acordo com os itens que representavam, e calculou-se a média dos mesmos, separando em dois grupos: o primeiro com sistema irrigado de produção e o outro, não irrigado.

A metodologia de custo de produção e análise utilizada foi a mesma adotada por Hoffman et al. (1987), onde o Custo de Produção Total (CPT) é dado pela soma CFT+CVT. Custo Médio (CM) ou Custo Total por unidade de produto é o custo total dividido pelas respectivas quantidades produzidas e pode ser obtido também pela soma dos Custos Fixos Médios com os Custos Variáveis Médios.

Tomou-se também como base o método de Oliveira e Holanda Filho (2009) que, em um trabalho sobre a mesma região, contabilizaram os custos de produção por saca beneficiada de café e por módulo de cinco hectares, que é a área típica de exploração de uma unidade familiar de produção no Estado de Rondônia. O autor destaca também que as propriedades, em geral, podem ser subclassificadas em propriedades que utilizam e as que não utilizam recursos de irrigação, sendo essa variável o principal diferenciador tecnológico entre as propriedades.

Dessa forma, o cálculo dos custos foi definido pelas seguintes variáveis:

$C T=C F+C V$,

em que CT são os custos totais; CF, os custos fixos; e CV, os custos variáveis. Os CF e CV foram dados pelas seguintes equações:

$$
C F=I M L+D E P+B E N
$$


$C V=M O D+I N S+E N E+I M P+M A N$

em que IML é a implantação da lavoura; DEP, a depreciação; BEN, as benfeitorias da propriedade; MOD, mão de obra contratada; INS, os insumos; ENE, energia e combustíveis; IMP, impostos e taxas; e MAN, manutenção de equipamentos e instalações.

Os números, como expressos nas equações de 1 a 3 , estão em valores absolutos e devem ser transformados em valores que sejam comparáveis entre unidades produtivas. Há duas formas de isso ser feito: dividir os resultados por sacas vendidas (produtividade por saca), ou por área de plantio (produtividade por área). Segundo Oliveira e Holanda Filho (2009), CFS são os custos fixos divididos pelo número de sacas, assim como os CVS são os custos variáveis também divididos pela quantidade total de sacas produzidas.

$$
\begin{aligned}
& C F S=\frac{I M L+D E P+B E N}{S A C A S} \\
& C V S=\frac{M O D+I N S+E N E+I M P+M A N}{S A C A S} .
\end{aligned}
$$

O cálculo da lucratividade absoluta $L$ é obtido pela subtração da receita total pelo custo total da produção do café, enquanto $L S$ é a lucratividade dividida pelo número de sacas.

$L=R-C T$,

$L S=\frac{R-C T}{S A C A S}$.

Uma vez coletados os dados, os mesmos foram agrupados e compilados de acordo com os itens que representavam e, então, calculou-se a média dos mesmos com base nas informações cedidas por cada propriedade. Ao final, fez-se o somatório das médias de cada item, chegando-se ao custo total médio. 
Operação em Mercados Futuros e Lucratividade da Propriedade Rural: Análise baseada nos Custos de Produção de Café Larissa Ananda Paiva Maciel, Carlos André da Silva Müller, Rosália Maria Passos da Silva

Para se chegar ao custo total médio, foram calculados custos variáveis médios como: mão de obra e serviços contratados; energia e combustível; impostos e taxas e manutenção de máquinas, bem como equipamentos e instalações. Esses custos foram somados aos custos fixos médios, sendo: implantação da lavoura, depreciação de máquinas, equipamentos e instalações e benfeitorias da propriedade.

\section{RESULTADOS E DISCUSSÃO}

A Figura 1 mostra o comportamento dos preços tanto no mercado físico quanto no mercado futuro de café para o município de Cacoal. Uma característica inerente a esses mercados deveria ser a correlação. Entretanto, percebe-se que o crescimento do valor dos contratos futuros de café arábica é superior à elevação dos preços físicos praticados na praça de Cacoal, em Rondônia, em especial na última fase, quando os preços dos contratos futuros se elevam significativamente.

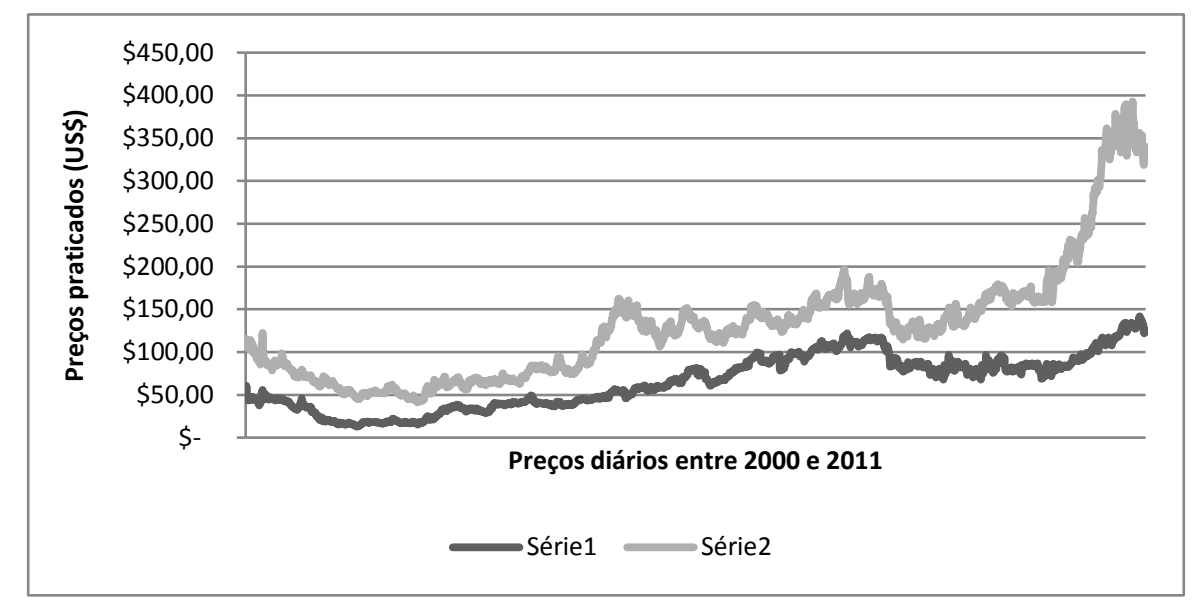

Figura 2: Evolução dos preços praticados de café robusta de Cacoal e preços dos contratos futuros de café arábica na BM\&F

Fonte: Dados de pesquisa.

Esse descolamento entre os preços provavelmente é o motivo pelo qual a cointegração entre os preços foi rejeitada e, portanto, a opção foi o uso do Modelo 
Vetorial Autorregressivo para determinação da estratégia de hedge. O resultado das estratégias de hegde é apresentado na Figura 3.

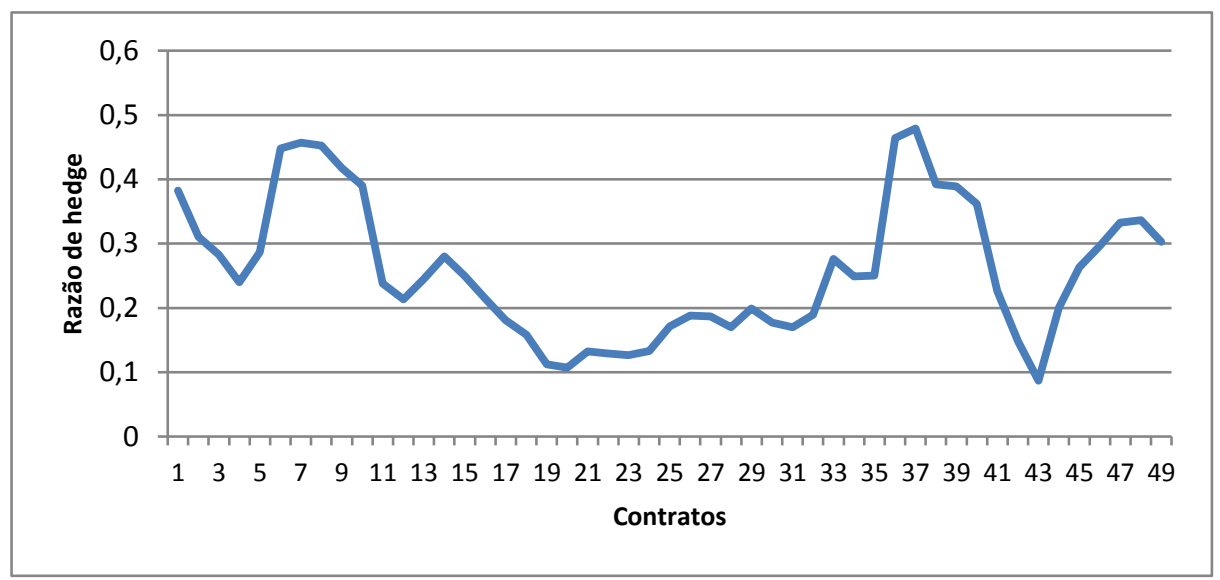

Figura 3: Evolução da razão de hedge por contrato.

Fonte: Dados de pesquisa.

A Figura 3 mostra a evolução das razões de hedge para os produtores de Cacoal para minimizar seus riscos de volatilidade de preços, por contrato. Verifica-se que, nos contratos, entre março e setembro de 2003 , as estratégias ficaram um pouco acima de 0,4 , o que significa que um produtor, para minimizar seus riscos, precisaria vender em torno de $40 \%$ da sua expectativa futura de comercialização física de sua produção. Essa proporção reduziu-se nos contratos subsequentes, elevando-se posteriormente, no ano de 2009.

Uma vez obtidas as razões de hedge, a etapa seguinte seria construir a evolução do preço efetivo, conforme os procedimentos metodológicos descritos. A condição ideal é de que os riscos fossem reduzidos pela atuação em mercados futuros e que os preços efetivos não destoassem significativamente dos preços à vista. A Figura 4 mostra como se comporta essa evolução. 
Operação em Mercados Futuros e Lucratividade da Propriedade Rural: Análise baseada nos

Custos de Produção de Café

Larissa Ananda Paiva Maciel, Carlos André da Silva Müller, Rosália Maria Passos da Silva

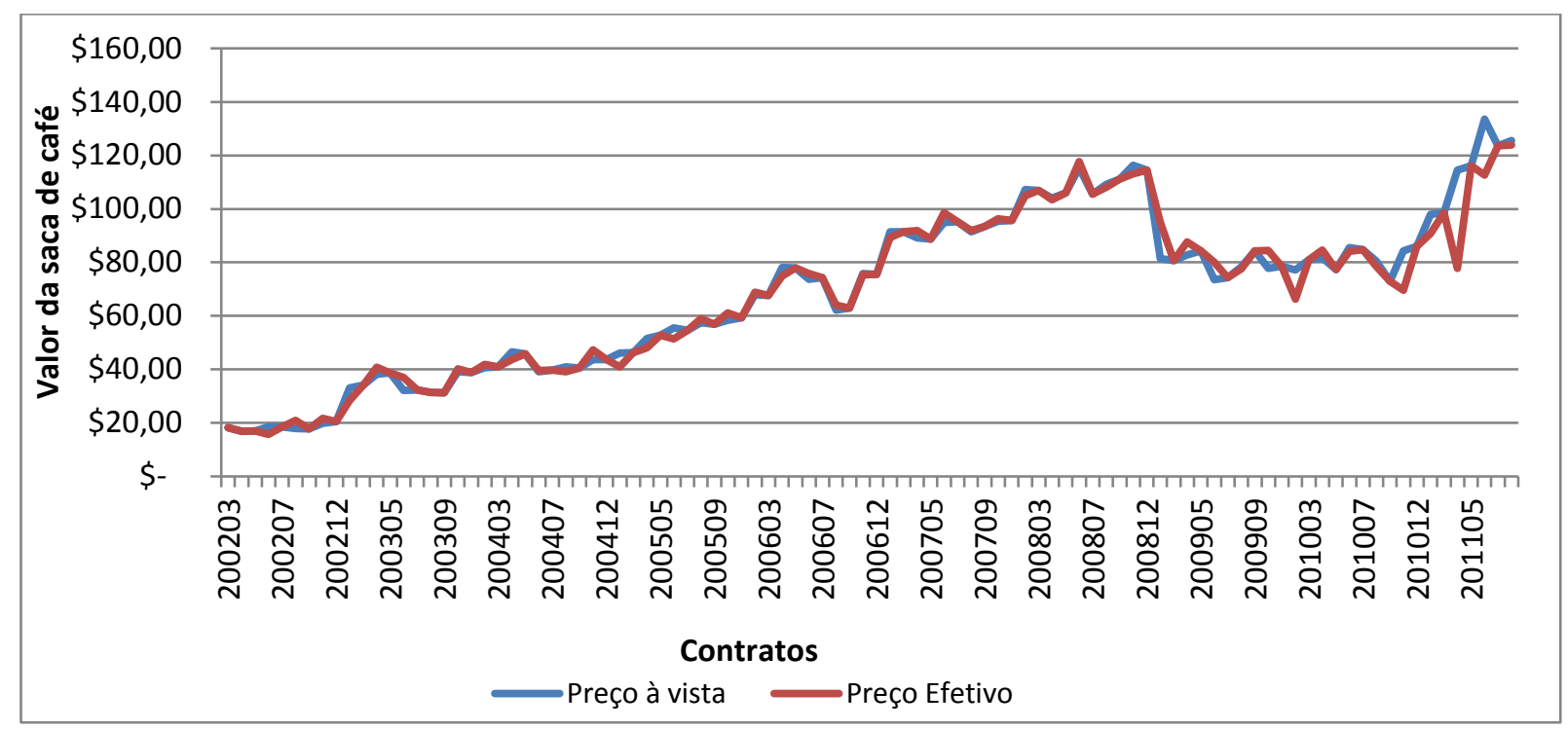

Figura 4. Comportamento dos preços à vista e efetivo durante o período compreendido entre 2002 e 2011 Fonte: Dados da Pesquisa.

Caso o produtor rural atuasse exclusivamente no mercado à vista, os preços seriam percebidos de acordo com a Figura 4, a qual tem um crescimento no início do período até 2008, momento em que o mercado de commodites sofreu uma queda generalizada, devido à crise financeira mundialmente estabelecida. Observa-se, de uma forma geral, que os preços efetivos acompanharam os preços à vista, mantendo forte correlação positiva, mesmo no momento da queda de preços.

Outro aspecto que deve ser salientado é que, a partir de 2009, os preços à vista de café robusta estiveram superiores aos preços efetivos. Certamente, nesse período, a atuação em mercados futuros não gerou resultados adequados em termos de preços percebidos, uma vez que, se não atuasse, os preços à vista gerariam maior lucro ao produtor. Esse resultado pode ser explicado pelo aumento do preço futuro da saca de café arábica, descolando-se do preço de café robusta de Cacoal, o que, na prática, gerou diminuição do preço efetivo em relação ao preço à vista.

Após a definição dos preços efetivos pela participação em mercados futuros, iniciou-se a pesquisa de campo para definição dos custos de produção. Foi verificado 
Operação em Mercados Futuros e Lucratividade da Propriedade Rural: Análise baseada nos Custos de Produção de Café Larissa Ananda Paiva Maciel, Carlos André da Silva Müller, Rosália Maria Passos da Silva

que as propriedades basicamente apresentam dois sistemas de produção: uma denominada tradicional, na qual não há irrigação, e outra irrigada (Tabela1).

Tabela 1. Área média destinada ao plantio de café robusta.

\begin{tabular}{|c|c|c|}
\hline \multicolumn{3}{|c|}{ Área destinada ao plantio de café (ha) } \\
\hline & Tradicional & Irrigado \\
\hline Média & 10,15 & 12,48 \\
\hline Máximo & 19,36 & 25,00 \\
\hline Mínimo & 03,63 & 02,42 \\
\hline Quantidade de produtores & $\mathbf{1 2}$ & $\mathbf{1 2}$ \\
\hline
\end{tabular}

Fonte: Dados da pesquisa.

A área destinada à plantação de café está, em média, 10,15ha por propriedade para o sistema tradicional na medida em que as propriedades que trabalham com 0 sistema irrigado apresentaram uma média de 12,48 hectares.

Quando se elaboram os custos de produção, percebe-se que os sistemas produtivos apresentam custos bastante diferentes, que afetam substancialmente o lucro por saca produzida, conforme pode ser observado na orçamentação descrita na Tabela 2. 
Operação em Mercados Futuros e Lucratividade da Propriedade Rural: Análise baseada nos

Custos de Produção de Café

Larissa Ananda Paiva Maciel, Carlos André da Silva Müller, Rosália Maria Passos da Silva

Tabela 2. Custo de produção da saca de café em sistema tradicional e irrigado em Cacoal/RO

\begin{tabular}{|c|c|c|c|c|}
\hline \multicolumn{6}{|c|}{ Orçamentação dos Custos de Produção } \\
\hline Item & \multicolumn{2}{|c|}{ Sistema Tradicional } & \multicolumn{2}{c|}{ Sistema Irrigado } \\
\hline Custo total (1+ 2) & 79,10 & $56,50 \%$ & 103,85 & $74 \%$ \\
\hline Custo variável & 64,71 & $46,22 \%$ & 91,78 & $66 \%$ \\
\hline Mão de obra e serviço contratado & 31,29 & $22,35 \%$ & 32,14 & $23 \%$ \\
\hline Insumos & 8,01 & $5,72 \%$ & 13,08 & $9 \%$ \\
\hline Energia e combustível & 12,11 & $8,65 \%$ & 27,13 & $19 \%$ \\
\hline Impostos e taxas & 7,18 & $5,13 \%$ & 8,56 & $6 \%$ \\
\hline Manutenção de máquinas, & 6,12 & $4,37 \%$ & 10,87 & $8 \%$ \\
\hline equipamentos e instalações & 14,39 & $10,28 \%$ & 12,07 & $9 \%$ \\
\hline Custo fixo & 8,18 & $5,84 \%$ & 3,39 & $2 \%$ \\
\hline Implantação da lavoura & 6,21 & $4,44 \%$ & 8,68 & $6 \%$ \\
\hline Depreciação de máquinas, & 1,92 & $1,37 \%$ & 6,38 & $5 \%$ \\
\hline equipamentos e instalações & 140,00 & $100,00 \%$ & 140 & $100 \%$ \\
\hline Benfeitorias & 60,90 & $43,50 \%$ & 36,15 & $26 \%$ \\
\hline Receita bruta & & & &
\end{tabular}

Fonte: Dados da Pesquisa

Conforme dados da Tabela 2, o sistema tradicional apresenta o menor custo de produção, somando, em média, $R \$ 79,10$ por saca, obtendo lucro médio de $R \$ 60,90$ por saca vendida. Nesse sistema, os maiores custos são refletidos pela mão de obra contratada, que gira em torno de $\mathrm{R} \$ 31,29$ por saca e pela energia e combustível consumidos na produção que somam, em média, $\mathrm{R} \$ 12,11$. Em contrapartida, o sistema irrigado apresenta custos mais elevados que giram em torno de $R \$ 103,85$ por saca, gerando lucro médio de $R \$ 36,15$, além do dispêndio realizado com mão de obra e combustível, que apresentam uma média de $R \$ 32,14$ por saca e $R \$ 13,08$ por saca respectivamente. Observa-se também um custo significativo de depreciação e manutenção de equipamentos e instalações, que varia, em média, de $R \$ 10,87$ por saca, sobretudo em função do uso de equipamentos de irrigação fixa.

Embora a lucratividade seja maior para o sistema não irrigado por saca, é importante salientar que esse resultado é perfeitamente compensado pelo aumento na 
produtividade por hectare. A Figura 5 apresenta a produtividade do sistema irrigado e tradicional dividido em quartis, de modo que é possível perceber que a produtividade do sistema irrigado de cafeicultura é significativamente superior à produtividade do sistema tradicional.

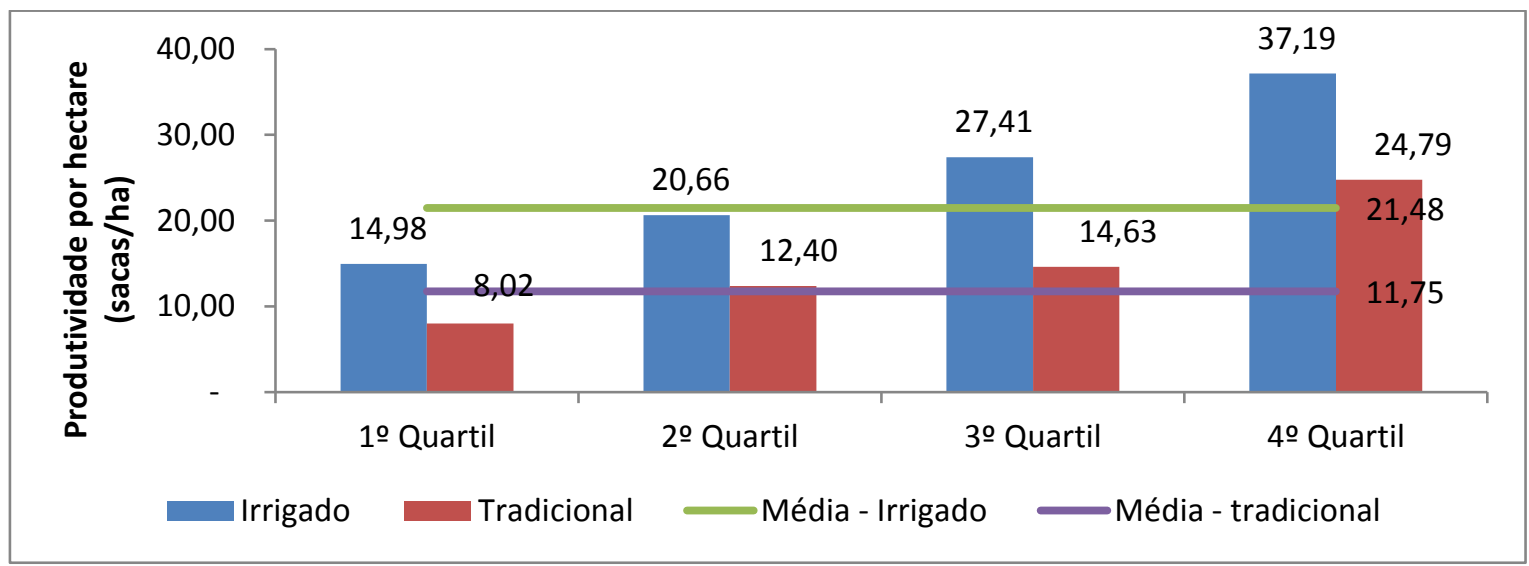

Figura 5. Produtividade média de sacas por hectare da linha 21, Cacoal, Rondônia Fonte: Dados da Pesquisa.

Em média, a produtividade da cafeicultura irrigada é de 21,48 sacas por hectare, na medida em que, na cafeicultura sem irrigação, a produtividade fica em 11,75 sacas por hectare, o que significa um acréscimo de aproximadamente $82 \%$, na média. Caso as propriedades fossem distribuídas em quartis, a superioridade da produtividade permaneceria em todos estes; por exemplo, no quarto quartil, enquanto o sistema tradicional produz, no máximo, aproximadamente 25 sacas por hectare, o sistema irrigado apresenta 37 sacas por hectare.

Entretanto, quando se observa a lucratividade por hectare, as vantagens de utilização da irrigação são muito menos perceptíveis. De fato, há grande similaridade entre os dois sistemas. Na média, a lucratividade por hectare daqueles que adotaram o sistema irrigado ficou em $\mathrm{R} \$ 1,27$ mil, enquanto que, para o sistema sem irrigação, ficou em $\mathrm{R} \$ 1,20$ (Figura 6). 


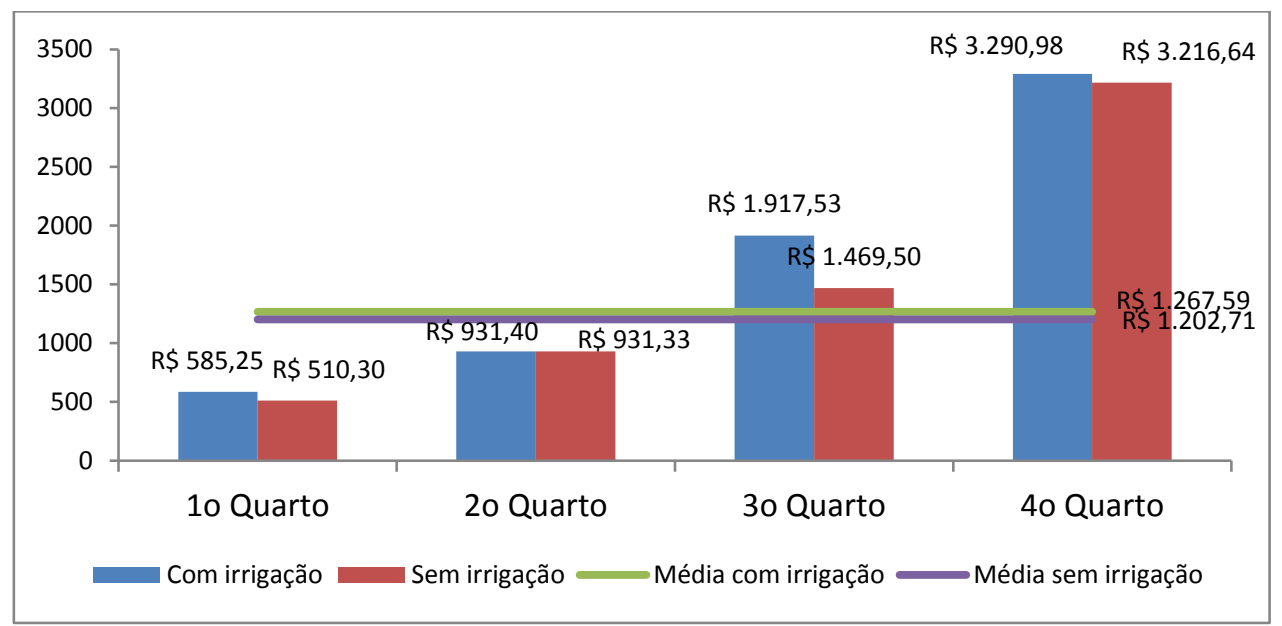

Figura 6. Lucratividade por hectare dividido em quartis Fonte: Dados da Pesquisa.

O segundo quartil, por exemplo, mostra que, em média, a lucratividade gerada pelo sistema tradicional é basicamente a mesma gerada pelo sistema irrigado de produção; a diferença mais significativa é encontrada no terceiro quartil, onde a lucratividade do sistema tradicional é, em média, $R \$ 1.470,00$, enquanto que, no irrigado, gira em torno de $\mathrm{R} \$ 1.920,00$. Em termos percentuais, esses valores representam uma vantagem de 5,39\% do sistema irrigado sobre o sistema tradicional.

Não se pode afirmar quais os fatores que contribuem para que a lucratividade do sistema tradicional seja tão similar à lucratividade do sistema irrigado; o que se pode supor é que este fato pode estar relacionado ao manuseio incorreto do sistema de irrigação fixa, como deixar a bomba ligada por muito tempo (o que pode aumentar os custos de combustível), ou mesmo, não manter a bomba ligada o tempo suficiente, o que pode prejudicar a floração da lavoura, diminuindo assim a produtividade.

Para inferir o quanto o preço efetivo é capaz de interferir na lucratividade do produtor rural, verificou-se, em termos percentuais, a oscilação do preço efetivo em relação ao preço à vista. De acordo com a Figura 7 , em cerca de $33 \%$ das vezes, o preço efetivo é superior ao preço à vista em até $5 \%$, que é a maior probabilidade. Considerando a possibilidade de os preços variarem entre menos $5 \%$ e mais $5 \%$, os resultados apontam para uma possibilidade de $61 \%$ dos casos. 


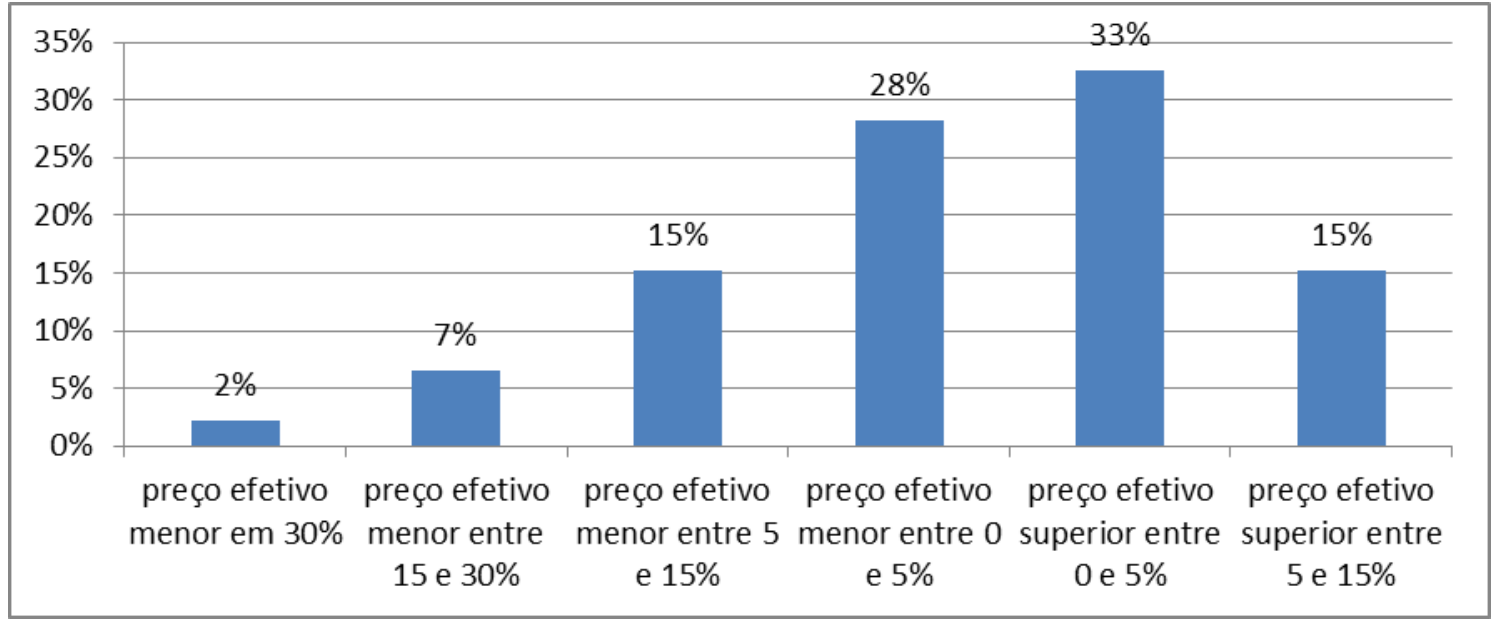

Figura 7. Oscilação percentual do preço efetivo em relação ao preço à vista e distribuição de probabilidade

Fonte: Dados da pesquisa.

De forma geral, as primeiras evidências indicam para uma concentração em termos de distribuição dos preços efetivos em relação ao preço à vista de café robusta praticado em Cacoal, o que indica que as estratégias de hedge podem beneficiar os produtores rurais, mesmo porque a extremidade negativa da distribuição que representaria um preço efetivo menor em 30\% ocorreu apenas em $2 \%$ das observações.

Para confirmar essa possibilidade, foi levantada a lucratividade do produtor rural, considerando essa distribuição de probabilidade do preço efetivo em relação ao preço à vista, a partir dos custos de produção médios da amostra, discutido anteriormente. Os resultados estão apresentados na Figura 8. 
Operação em Mercados Futuros e Lucratividade da Propriedade Rural: Análise baseada nos

Custos de Produção de Café

Larissa Ananda Paiva Maciel, Carlos André da Silva Müller, Rosália Maria Passos da Silva

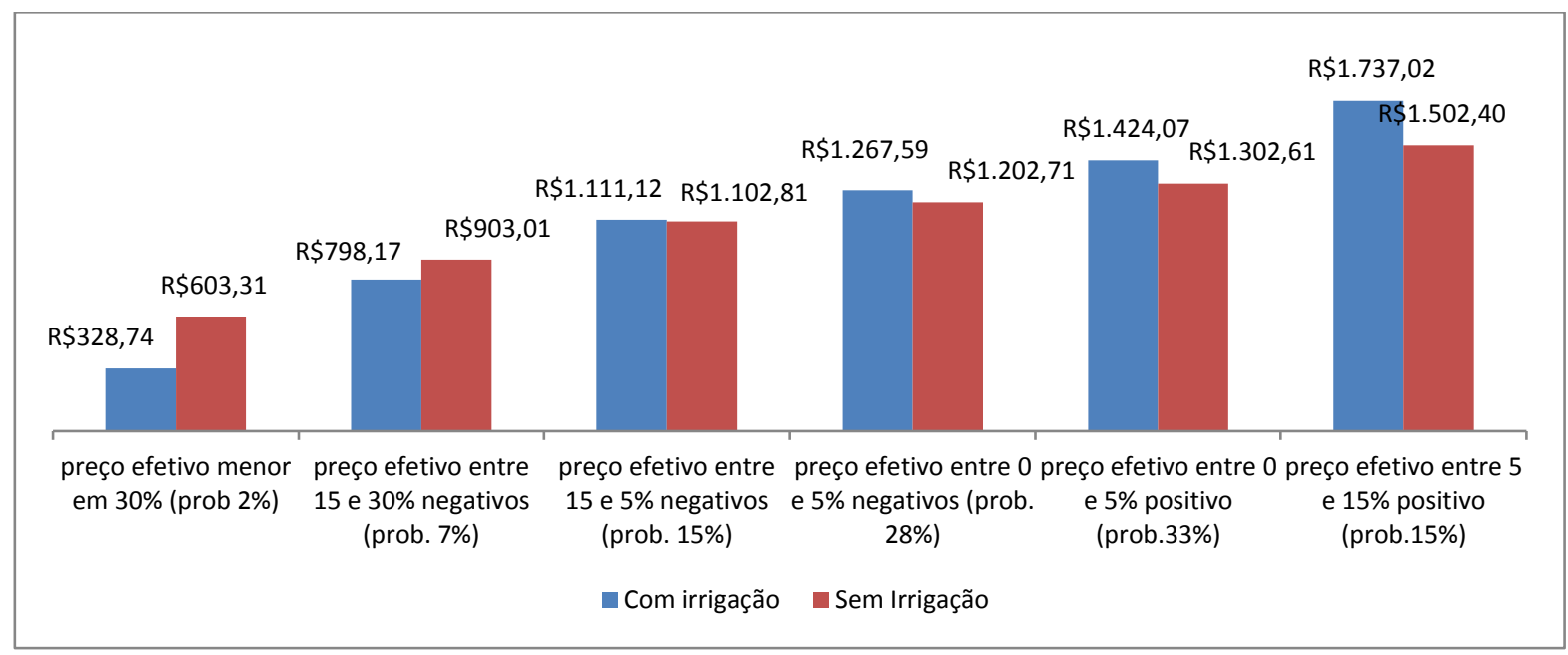

Figura 8. Probabilidades de lucro por hectare baseado nos preços efetivos Fonte: Dados da pesquisa.

Verifica-se que o impacto da variação do preço efetivo em relação à lucratividade por hectare é diferenciado, dependendo dos sistemas produtivos. Impactos negativos fortes fazem os sistemas produtivos sem irrigação serem mais vantajosos do que os sistemas irrigados. Isso ocorre quando os preços efetivos recuarem em $15 \%$ ou mais do preço à vista (incluindo menos que 30\%). A probabilidade dessa ocorrência é de $9 \%$ (soma da ocorrência entre $15 \%$ e $30 \%$ e menos que $30 \%$ ).

Caso o preço efetivo recue entre $5 \%$ e $15 \%$, a lucratividade dos dois sistemas é praticamente equivalente, e, acima disso, os sistemas irrigados apresentam lucratividade superior aos sistemas tradicionais, sem irrigação.

De forma geral, de acordo com as possibilidades levantadas neste trabalho, a maior probabilidade de ocorrência está em uma lucratividade que gira em torno dos preços praticados à vista. Esses resultados indicam que a utilização pode beneficiar os produtores de café de Cacoal. 
Operação em Mercados Futuros e Lucratividade da Propriedade Rural: Análise baseada nos

Custos de Produção de Café

Larissa Ananda Paiva Maciel, Carlos André da Silva Müller, Rosália Maria Passos da Silva

\section{CONSIDERAÇÕES FINAIS}

O uso de estratégias de hedge para reduzir a volatilidade de preços e assegurar a comercialização física da atividade agropecuária está amplamente difundida na literatura que trata do uso de mercados futuros com essa finalidade. Poucos são os estudos que mostram esse mecanismo como ineficiente para a gestão de riscos. É certo também que produtores rurais não usam mercados futuros, mesmo aqueles mais sofisticados, propensos a [investir] em tecnologia.

Nessa assertiva, sob a indagação de quais os efeitos da atuação em mercados futuros sobre a lucratividade dos produtores rurais, buscou-se compreender 0 comportamento de sua principal variável, o preço efetivo. A partir dos resultados, não se pode afirmar que não há riscos inerentes ao uso da ferramenta; entretanto, o comportamento do preço efetivo pareceu ser adequado, mesmo considerando que o café cultivado em Rondônia é o robusta, na medida em que a negociação na bolsa de mercadorias é o café arábica.

No tocante ao orçamento do produtor rural, constatou-se que, entre os produtores, a preocupação de gerência das propriedades rurais geralmente é maior em relação ao aumento da produtividade na cultura de café e à inovação tecnológica. Normalmente, o registro de dados sobre custos, despesas e investimentos realizados nas propriedades deixa de ser feito, dificultando a mensuração da lucratividade. De modo geral, o que se pode afirmar é que há dois orçamentos distintos: um para as culturas de café tradicionais e outro para as culturas irrigadas, no que se pode observar que os custos da cultura tradicional são significativamente inferiores ao da cultura irrigada.

Contudo, essa disparidade entre custos mostrou-se compensatória pelos ganhos de produtividade das culturas irrigadas. Por outro lado, não foi possível assegurar que maior produtividade representasse maior lucro, o que deve ser observado em pesquisas posteriores. Supõe-se que o uso de novas tecnologias não esteja sendo feito de forma adequada. 
Operação em Mercados Futuros e Lucratividade da Propriedade Rural: Análise baseada nos

Custos de Produção de Café

Larissa Ananda Paiva Maciel, Carlos André da Silva Müller, Rosália Maria Passos da Silva

Acreditou-se, a priori, que o descolamento dos preços, bem como a não identificação de co-integração estatística poderia interferir nos resultados negativamente; no entanto, essa hipótese não pode ser comprovada. Assim, os efeitos negativos sobre a lucratividade não podem ser argumentos para inserção nos mercados futuros para os produtores rurais pesquisados. Uma sugestão é a formação de cooperativas específicas para este fim, agregando volume nas negociações em Bolsas de Mercadorias.

Deixa-se como indagação, para pesquisas posteriores, levantamentos como este em outras regiões que não estejam tão distantes dos centros tradicionais de comercialização de commodities.

\section{REFERÊNCIAS}

AGUIAR, D. R. D. (2003). ERU 564. Mercados agroindustriais e de futuros. (MBA Gestão do agronegócio). Universidade Federal de Viçosa- MG, Departamento de Economia Rural.

ASSAF NETO, A. (2003). Finanças corporativas e de valor. São Paulo: Atlas, 609 p.

BARROS, A. M.; AGUIAR, D. R. D. (2005). Gestão do risco de preços de café arábica: uma análise por meio do comportamento da base. Revista de Economia e Sociologia Rural, Brasília, v. 43 (3): 443-467.

BITENCOURT, W. A.; SILVA, W. S.; SÁFADI, T. (2006). Hedge dinâmicos: Uma evidência para contratos futuros brasileiros. Organizações rurais \& agroindustriais, Lavras, v. 8 (1):71-78.

BORELLA, J. B. (2004). O Hedge utilizando contratos futuros como estratégia de gestão de riscos de preços da soja. Estudo de Caso da Cooperativa Tritícola Mista Alto Jacuí Ltda. Porto Alegre, RS. (Dissertação de Mestrado). Universidade Federal do Rio Grande do Sul. UFRGS, $70 \mathrm{p}$.

BRASIL, C. E. A. (2011). Efeitos da percepção de riscos em operações em mercados futuros: o caso de Produtores de Café Robusta em Cacoal, Rondônia. Porto Velho, RO. (Dissertação de Mestrado). Universidade Federal de Rondônia, 99 p.

BRESSAN, A. A. (2004). Tomada de decisão em futuros agropecuários com modelos de previsão de séries temporais, RAE - eletrônica, v. 3 (1), art. 9. 
Operação em Mercados Futuros e Lucratividade da Propriedade Rural: Análise baseada nos

Custos de Produção de Café

Larissa Ananda Paiva Maciel, Carlos André da Silva Müller, Rosália Maria Passos da Silva

BURGO, M. N. (2005). Caracterização espacial de riscos na agricultura e implicações para o desenvolvimento de instrumentos para seu gerenciamento. São Paulo, Piracicaba. (Dissertação de Mestrado). Escola Superior de Agricultura "Luiz de Queiroz", 96 p.

CONAB. (2008). Companhia Nacional de Abastecimento. Acompanhamento da safra brasileira: Café - Safra 2007/2008, quarta estimativa. Brasília: CONAB.

CARVALHO, N. M. (1999). Evidenciação de derivativos. Caderno de Estudos. São Paulo, n. 20: p.1-16.

CARVALHO, M. L. S.; GODINHO, M. L. F. (2005). Consequences of the 2003 Cap Reform on a Mediterranean Agricultural System of Portugal. XIth Congress of the EAAE (European Association of Agricultural Economists), "The future of rural Europe in the Global Agri-food System", Copenhagen, Denmark, August 24-27.

COIMBRA, F. C. (2004). Gestão estratégica de riscos: Instrumento de Criação de Valor. (MBA Economia do Setor Financeiro). Universidade de São Paulo - USP, São Paulo, $\mathrm{SP}$.

CONAB. (2011). Companhia Nacional de Abastecimento. 2a Estimativa, 2011. Disponível em: < www.conab.gov.br> Acesso em: jan. 2011.

CRUZ JÚNIOR, J. C. (2009). Modelo de razão de hedge ótima e percepção subjetiva de riscos nos mercados futuros. (Tese de Doutorado). Escola Superior de Agricultura "Luiz de Queiroz", Universidade de São Paulo - USP, Piracicaba, São Paulo, SP. 100 p.

EDERINGTON, L. H. (1979). The hedging performance of new futures markets. The Journal of Finance, v. 34 (1): 157-170.

FASIABEN, M. C. R.; BACCHI, M. R. P.; PERES, F. C. (2003). Fronteira de eficiência econômica em condições de risco: estudos de caso de sistemas de produção familiar da região centro-sul do Paraná. Agricultura. São Paulo, v. 50, n. 1, p. 93- 107.

FARHI, M. Derivativos financeiros: hedge, especulação e arbitragem. (1999). Economia e sociedade, n.13. Campinas: IE/Unicamp, p. 93-114, dez.

, D.H.; MARQUES, P. V.; MACHADO, H.M. (1999). O risco de base e a efetividade do hedge para negócios do café em Minas Gerais. Organizações Rurais e Agroindustriais, Lavras, v. 1, n. 1, p. 42-50.

GHOSH, A. (1993). Hedging with stock index futures: estimation and forecasting with error correction model. Journal of Future Markets, v. 13, n. 7, p. 743-752. 
Operação em Mercados Futuros e Lucratividade da Propriedade Rural: Análise baseada nos

Custos de Produção de Café

Larissa Ananda Paiva Maciel, Carlos André da Silva Müller, Rosália Maria Passos da Silva

HERBST, A. F.; KARE, D. D.; MARSHALL, J.F. (1993). A time varying, convergence adjusted, minimum risk futures hedge ratio. Advances in futures and options research, $v$. 6 , p. 137-155.

HOFFMANN, R. et al. (1976). Administração da empresa agrícola. São Paulo: Pioneira, 1976. 323 p.

HULL, J. (1996). Introdução aos mercados futuros e de opções. (2. ed). São Paulo: Bolsa de Mercadorias \& Futuros.

LAMOUNIER, W. M. (2002). Comportamento dos preços no mercado spot de café do Brasil: Análise nos Domínios do Tempo e da Frequência. Viçosa: UFV. (Tese de Doutorado). Universidade Federal de Viçosa.

LEFTWICH, R. H. (1974). O sistema de preços e alocação de recursos. (4 ed). rev. São Paulo: Pioneira. 399 p.

LOPES, M. A.; CARVALHO, M. F. de. (2000). Custo de produção do leite. Universidade Federal de Lavras - UFLA, Lavras, MG. 41 p.

MARTINS, C. M. F. (2005). A volatilidade nos preços futuros do café brasileiro e seus principais elementos causadores. 154 p. (Dissertação de Mestrado). Universidade Federal de Lavras - UFLA, Lavras, MG. 154 p.

MATTOS, F. L. (2000). Utilização de contratos futuros agropecuários em carteiras de investimento: Uma Análise de Viabilidade. São Paulo: Bolsa de Mercadorias \& Futuros.

MYERS, R. J.; THOMPSON, S. R. (1989). Generalized optimal hedge ratio estimation. American Journal of Agricultural Economics, v. 60, p. 858-867.

MÜLLER, C. A. S.; MOURA, A. D.; LIMA, J. E. (2009). Efetividade de hedge para o café arábica no Brasil: modelos matemáticos versus aspectos práticos, p. 251-270. In: RUFINO, J. L. S.; ARÊDES, A. F. (Org.). Mercados interno e externo do café brasileiro. Embrapa Informações Tecnológicas: Brasília.

OLIVEIRA, S. J. M.; HOLANDA FILHO, F. Z. (2009). Aspectos econômicos, ambientais e sociais da produção cafeeira em diferentes sistemas em Rondônia. Comunicado técnico EMBRAPA, Porto Velho, out.

SOUZA, R. D. et al. (1989). Administração da fazenda. Rio de Janeiro: Globo. 70 p. 


\section{Operação em Mercados Futuros e Lucratividade da Propriedade Rural: Análise baseada nos Custos de Produção de Café Larissa Ananda Paiva Maciel, Carlos André da Silva Müller, Rosália Maria Passos da Silva}

TONIN, J. M.; BRAGA, M. J.; COELHO, A. B. (2009). Efetividade de hedge do milho com contratos futuros da BM\&F: uma aplicação para a região de Maringá. Revista de Economia, v. 35, n. 1 (ano 33), p. 117-142, jan./abril.

ZEN, S.; BRAGATO, I. R.; SPERS, E. E. (2005). Diversificação de atividades como gerenciamento de risco na agricultura. In: Congresso Brasileiro de Economia e Sociologia Rural, 2005, Ribeirão Preto.

Data de Submissão: 15/06/2015

Data de Aceite: 17/05/2016 